\title{
CONJUNTIVITIS FOLICULAR CRÓNICA EN EL LACTANTE
}

\section{NEWBORN CHRONIC FOLLICULAR CONJUNCTIVITIS}

\author{
RUIZ-DEL-RÍO N ${ }^{1}$, RODRÍGUEZ-PRADO $\mathrm{S}^{1}$, MARTÍNEZ-ORMAECHEA E ${ }^{1}$, AGÜERO-BALBIN J ${ }^{2}$, \\ BELTRÁN-NÚNẼEZ P ${ }^{1}$, MARTÍNEZ-SANZ F²
}

\section{RESUMEN}

Caso clínico: Se presenta un caso de conjuntivitis folicular crónica del lactante que debuta como ptosis y dacriorragia. Mediante técnica de reacción en cadena de polimerasa (PCR) se diagnosticó Chlamydia trachomatis como agente etiológico y se trató con eritromicina tópica y sistémica. El contagio se produjo en el canal del parto.

Discusión: La conjuntivitis de inclusión del lactante es muy infrecuente en nuestro medio. El método diagnóstico más sensible y específico es la PCR. Se debe identificar la fuente de contagio y hacer un tratamiento precoz y completo de todos los portadores para evitar las complicaciones de la cronicidad.

Palabras clave: Conjuntivitis folicular crónica, lactante, Chlamydia trachomatis, paratracoma, PCR.

\begin{abstract}
Case report: A case of chronic follicular conjunctivitis in an infant presenting with ptosis and dacryorrhea is reported. Polymerase chain reaction (PCR) test identified Chlamydia trachomatis as the causative agent. The patient was treated with topic and systemic erythromycin. The infection was probably transmitted during delivery.

Discussion: Chronic follicular conjunctivitis in infants is very uncommon in our environment. The most sensitive and specific diagnostic test is PCR. It is necessary to identify the original focus of infection and to provide specific treatment to all the carriers as soon as possible to avoid and prevent chronic complications (Arch Soc Esp Oftalmol 2008; 83: 559-562).
\end{abstract}

Key words: Chronic follicular conjunctivitis, infant, Chlamydia trachomatis, paratracoma, PCR.

\section{INTRODUCCIÓN}

La mayoría de las conjuntivitis foliculares diagnosticadas en nuestro medio son de etiología vírica, destacando las causadas por virus herpes simple (VHS) y adenovirus. Las crónicas son infrecuentes (tabla I) (1); entre ellas destacan las conjuntivitis de inclusión.

Las conjuntivitis neonatales son enfermedades de declaración obligatoria. La causa más frecuente del mundo es la conjuntivitis de inclusión por Chlamydia trachomatis, aunque en nuestro medio lo más

\footnotetext{
Recibido: 10/1/07. Aceptado: 18/8/08.

Hospital Universitario Marqués de Valdecilla. Santander. Cantabria. España.

1 Licenciado en Medicina.

2 Doctor en Medicina.

Correspondencia:

Noemí Ruiz del Río

La Dreda, 167 A. Villapresente

39539 Reocín (Cantabria)

España

E-mail: noeruizdelrio@yahoo.es
} 
Tabla I. Clasificación etiológica de las conjuntivitis foliculares modificada ${ }^{1}$

\begin{tabular}{ll}
\hline Agudo & \multicolumn{1}{c}{ Crónico } \\
\hline Adenovirus & Conjuntivitis inclusión del adulto \\
RNA virus & Conjuntivitis inclusión neonatal \\
Togavirus & Chlamydia trachomatis \\
Picornavirus & Psitacosis \\
Poxvirus & Moraxella \\
Ortomixovirus & Enfermedad de Lyme \\
VHS & Farmacológica \\
VEB & Moluscum \\
& Rosácea \\
\hline \hline
\end{tabular}

frecuente sean las conjuntivitis bacterianas, destacando la gonocócica (1).

La Chlamydia trachomatis es un bacilo intracelular obligado, patógeno exclusivo humano. Los serotipos A, B y C son los responsables del tracoma, las cepas L del linfogranuloma venéreo y la proctocolitis hemorrágica y los serotipos $\mathrm{D}-\mathrm{K}$ producen enfermedades de transmisión sexual e infecciones perinatales, típicamente conjuntivitis de inclusión y neumonitis intersticial.

Tanto el diagnostico de la conjuntivitis neonatal por chlamydia como por gonococo requieren un alto índice de sospecha y un tratamiento precoz con antibioterapia sistémica.

\section{CASO CLÍNICO}

Paciente de sexo femenino y 7 meses de edad con ptosis leve unilateral (fig. 1) y dacriorragia con el

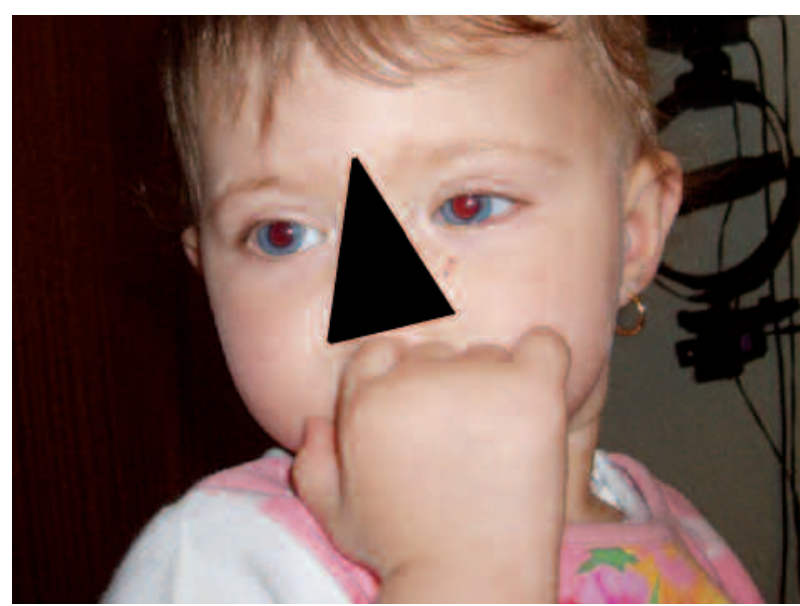

Fig. 1: Situación basal de la paciente. Leve ptosis unilateral izquierda. llanto y a la expresión del saco lagrimal desde los quince días de vida. Nació en España y su madre procedía de Europa del Este. En la exploración oftalmológica se apreció una pseudomembrana subtarsal superior y adenopatía preauricular izquierdas, sin secreción ni hiperemia, presentaba pannus superficial en el área límbica superior. El lavado de la vía lagrimal fue permeable y el cultivo del exudado conjuntival negativo. En el estudio inicial se realizó una resonancia magnética y una exploración otorrinolaringológica que descartaron patología de senos paranasales y del sistema de drenaje lagrimal. Se inició tratamiento tópico con tobramicina y dexametasona. Un mes después se observó una resolución parcial de la ptosis y total de la pseudomembrana. Dos meses después persistían folículos subtarsales en distinto estadio (fig. 2), por lo que se solicitó identificación de Chlamydia trachomatis por PCR (reacción en cadena de polimerasa) que resultó positiva. Se inició tratamiento tópico con eritromicina ungüento y eritromicina oral (50 mgrs/ $\mathrm{kg} /$ día en 4 dosis) durante 14 días. Al finalizar el tratamiento los hallazgos clínicos prácticamente habían desaparecido. Se practicó un estudio con PCR del exudado conjuntival y de orina de los individuos que convivían en el núcleo familiar. La única prueba que resultó positiva fue la orina de la madre, gestante de 29 semanas. Sin embargo, el cultivo de cérvix materno resultó negativo para Chlamydia trachomatis. Se pautó tratamiento sistémico a los padres con eritromicina (500 mg/6 h) durante 7 días. La erradicación del germen se confirmó mediante PCR del exudado conjuntival de la paciente y de la orina materna.

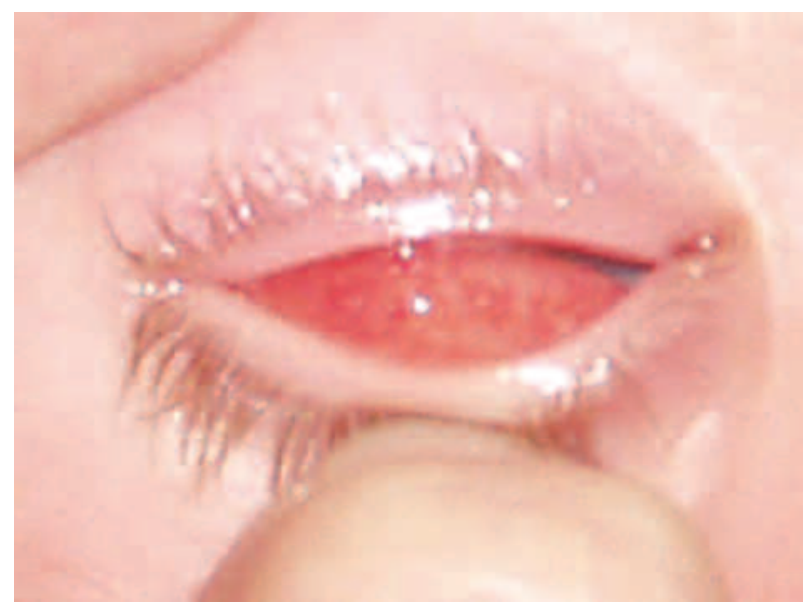

Fig. 2: Folículos subtarsales en el párpado superior en distinto estadio evolutivo. 


\section{DISCUSIÓN}

La causa más frecuente de conjuntivitis neonatal en el mundo es la conjuntivitis de inclusión; una entidad prácticamente erradicada en nuestro medio. Está causada por Chlamydia trachomatis de los serotipos D-K. Se manifiesta clínicamente como una conjuntivitis purulenta iniciada entre 5-12 días después del nacimiento, sin folículos en fase aguda, que en casos graves desarrolla pseudomembranas y neovascularización corneal1.

En nuestro medio la profilaxis neonatal se efectúa con eritromicina ungüento o nitrato de plata, ambas pautas previenen de la conjuntivitis gonocócica o bacteriana, pero no de la producida por Chlamydia. La solución de povidona iodada al $2,5 \%$ es igual de eficaz frente a Staphylococcus aureus y Neisseria gonorrhoeae y es además eficaz frente a Chlamydia trachomatis, presentando menor incidencia de conjuntivitis tóxica (2).

La conjuntivitis por Chlamydia trachomatis infantil es una entidad infradiagnosticada, presenta un curso subclínico autolimitado y suele interpretarse como una conjuntivitis vírica (3).

El método diagnóstico con mayor sensibilidad y especificidad es la PCR, debiendo practicarse al paciente y los convivientes. El tratamiento debe aplicarse a los individuos que resulten positivos y a sus parejas sexuales hasta tener una PCR confirmatoria negativa.

En cuanto a la cronicidad se barajan posibilidades como son las reinfecciones, la susceptibilidad personal (4), las condiciones higiénicas, siendo posible el contagio por vectores (zonas endémicas) y la patogenicidad del microorganismo.

Sin tratamiento adecuado la conjuntivitis folicular por chlamydia se cronifica y puede producir un paratracoma, una entidad producida por los serotipos D-K en áreas no endémicas que genera lesiones cicatriciales paralelas al tracoma.

Cuando se diagnostica una conjuntivitis neonatal por Chlamydia trachomatis la madre es la transmi- sora en el $87 \%$ de los casos (5). Es muy frecuente la colonización de la orofaringe, lo que podría ser el foco de posibles reinfecciones (5).

El tratamiento de elección en adultos es la eritromicina sistémica, $500 \mathrm{mg} / 6 \mathrm{~h}$ durante 7 días, no precisando tratamiento tópico simultáneo. Aunque se trata de un tratamiento seguro y efectivo, en los pacientes no respondedores, puede repetirse la pauta o utilizar otros tratamientos de segunda elección, como son: azitromicina 1 gr/día durante 7 días, doxiciclina $100 \mathrm{mg} / 12 \mathrm{~h}$ durante 7 días, u ofloxacino $300 \mathrm{mg} / 12 \mathrm{~h}$ durante 7 días.

La conjuntivitis neonatal por Chlamydia trachomatis es más prevalente de lo sospechado, particularmente en ambientes socioeconómicos desfavorecidos. Es importante identificar la fuente de contagio e iniciar un tratamiento precoz y eficaz para prevenir las cicatrices en los casos que pudieran cronificarse. A pesar de que las conjuntivitis crónicas que cursan con dacriorrragia son muy infrecuentes, son muy sugestivas de infección por Chlamydia trachomatis, debiendo incluir siempre en el diagnostico diferencial otras posibles entidades potencialmente graves.

\section{BIBLIOGRAFÍA}

1. Tasman W, Jaeger EA. Duanes's Clinical Ophthalmology. CD-ROM ed; Philadelphia: Lippincott Willians \& Wilkins; 2005.

2. Isenberg SJ, Apt L, Wood M. A controlled trial of povidone-iodine as prophylaxis against ophthalmia neonatorum. N Engl J Med 1995; 332: 562-566.

3. Uchio E, Takeuchi S, Itoh N, Matsuura N, Ohno S, Aoki K. Clinical and epidemiological features of acute follicular conjunctivitis with special reference to that caused by herpes simplex virus type 1. Br J Ophthalmol 2000; 84: 968972.

4. Bobo LD, Novak N, Munoz B, Hsieh YH, Quinn TC, West $S$. Severe disease in children with trachoma is associated with persistent Chlamydia trachomatis infection. J Infect Dis 1997; 176: 1524-1530.

5. Stenberg K, Mardh PA. Genital infection with Chlamydia trachomatis in patients with chlamydial conjunctivitis: unexplained results. Sex Transm Dis 1991; 18: 1-4. 